\title{
Lateral Pterygoid Muscle Location in Relation to Preauricular Skin Measured from CT Scans among a Sample of Yemeni
} Adults

\author{
Nashwan H Al-Tairi ${ }^{1}$, Yaser A Al-Sharaee ${ }^{2}$, Mohammed N Alhajj ${ }^{3}$
}

\begin{abstract}
Aim: The aim of this study was to determine the lateral pterygoid muscle (LPM) in relation to preauricular skin measured from computed tomography (CT) scan measurements.

Materials and methods: CT scans of 160 patients aged between 18 and 75 years were retrospectively collected and analyzed, and the distances were measured to determine the location of the LPM center in relation to the preauricular skin. On axial CT crossing the maximum muscle width, two lines [the first line is below the center of the zygomatic arch (first position), while the second line was $5 \mathrm{~mm}$ posterior to the first one (second position)] were drawn from the preauricular skin to the medial border and then extended to the lateral border of the muscle. These measurements were used to calculate the distance to the center of the muscle mathematically. Data were statistically analyzed, and the differences between both genders and both sides were investigated. The level of significance was set at $p$-value $<0.05$.

Results: Males displayed larger mean values in two positions ( $36.6 \pm 2.25$ and $35.97 \pm 4.19$, respectively) than females ( $33.66 \pm 4.46$ and $32.80 \pm 3.21$, respectively). The difference between both genders was found to be statistically significant. Measurements on the right side were also larger than those on the left side, but with no significant difference.

Conclusion: LPM center can be approached safely in males by inserting the needle about $36 \mathrm{~mm}$ at the first position and $33 \mathrm{~mm}$ at the second position. However, in females, these distances are located $3 \mathrm{~mm}$ shorter in both positions.

Clinical significance: The outcome of this study will provide the clinicians with measurements that can help in directing the needle or electromyography (EMG) electrode during the extraoral injection technique of the LPM.

Keywords: CT scan, Dystonia, Lateral pterygoid muscle, Preauricular skin.

The Journal of Contemporary Dental Practice (2021): 10.5005/jp-journals-10024-3098
\end{abstract}

\section{INTRODUCTION}

The lateral pterygoid muscle (LPM) has been generally described as a muscle composed of two separate heads: the superior (upper) head and the inferior (lower) head. ${ }^{1-3}$ The superior head of the muscle is reported to have various patterns of insertion; in some reports, the superior head inserts into the articular disc, ${ }^{2,4}$ whereas in other reports, it inserts into the articular disc and the pterygoid fovea of the mandible. ${ }^{5,6}$ However, some authors $^{7-10}$ reported that according to precise morphological studies, the LPM is not clearly divided into distinct parts. The LPM plays an important role in jaw movement and is thought to play an important part in the control and/or stabilization of the joint during mastication and speech. ${ }^{11-13}$ This muscle has been implicated in disease conditions, such as myositis and oromandibular dystonia. ${ }^{14,15}$

Recently, improved tissue-imaging methods have provided the means to better determine the size and location of the muscles. It can differentiate tissues based on their attenuation characteristics, which depend on their density and the electron per unit mass. ${ }^{16}$ Nowadays, multi-slice spiral CT (MSCT) enables the acquisition of three-dimensional (3D) volume images of the human body while improving the speed scanning considerably as compared to previous systems. ${ }^{17}$ Submillimeter scanning is feasible with the modern MSCT systems having broad detector panels that may cover the whole region of interest per rotation. ${ }^{18}$

\footnotetext{
1,2Department of Oral and Maxillofacial Surgery, Faculty of Dentistry, Thamar University, Dhamar, Yemen

${ }^{3}$ Department of Prosthodontics, Faculty of Dentistry, Thamar University, Dhamar, Yemen
}

Corresponding Author: Mohammed N Alhajj, Department of Prosthodontics, Faculty of Dentistry, Thamar University, Dhamar, Yemen, e-mail: m.n.alhajj@hotmail.com

How to cite this article: Al-Tairi NH, Al-Sharaee YA, Alhajj MN. Lateral Pterygoid Muscle Location in Relation to Preauricular Skin Measured from CT Scans among a Sample of Yemeni Adults. J Contemp Dent Pract 2021;22(5):522-526.

Source of support: Nil

Conflict of interest: None

Injection of botulinum toxin into LPM has been reported in the management of LPM dystonia, ${ }^{14,15,19,20}$ recurrent TMJ dislocation, ${ }^{21-23}$ myofascial pain, ${ }^{24}$ and anterior disc displacement. ${ }^{25}$ Dry needling of LPM trigger points has been tried in myofascial pain management. ${ }^{26,27}$ The location of the injection site in the muscle body could change the spread of the botulinum toxin, this fact being responsible for side effects such as a diffusion to nearby muscles. Diffusion into the pharyngeal muscles is responsible for dysphagia, and injection in soft palate muscles can lead to dysphonia. ${ }^{28-30}$ The

\footnotetext{
() Jaypee Brothers Medical Publishers. 2021 Open Access This article is distributed under the terms of the Creative Commons Attribution 4.0 International License (https://creativecommons.org/licenses/by-nc/4.0/), which permits unrestricted use, distribution, and non-commercial reproduction in any medium, provided you give appropriate credit to the original author(s) and the source, provide a link to the Creative Commons license, and indicate if changes were made. The Creative Commons Public Domain Dedication waiver (http://creativecommons.org/publicdomain/zero/1.0/) applies to the data made available in this article, unless otherwise stated.
} 
penetration depth to LPM has been reported only in a few studies that included a limited number of subjects. Mahan et al. ${ }^{31}$ studied LPM activity, in nine subjects, using electromyography (EMG). During EMG electrode placement, the penetration distance from skin to LPM was about 35 to $50 \mathrm{~mm}$. Five cases of TMJ dislocation were managed by Fu et al., ${ }^{23}$ where they inject botulinum toxin into LPM. The needle was advanced at a right angle to the skin, and the LPM was found at a depth of 3 to $4 \mathrm{~cm}$. Alexoudi et al. ${ }^{19}$ treated a woman, presented with LPM dystonia, by EMG-assisted injection of botulinum toxin into LPM. A needle electrode was inserted 3 to $4 \mathrm{~cm}$ until it was contacted with the muscle.

To the best of our knowledge, there is no study so far that evaluated the location of LPM in relation to preauricular skin among adults. The aim of the present study, therefore, was to evaluate the location of LPM center from computed tomography (CT) scans in relation to preauricular skin. The outcome of this study will provide the clinicians with measurements that can help in directing the needle or EMG electrode during the extraoral injection technique of the LPM.

\section{Materials and Methods}

The study population comprised 160 subjects who had undergone CT scan imaging for craniofacial diagnosis in a private medical hospital in Dhamar city, Yemen, from October 2016 to October 2020. The study protocol was approved by the Ethical Research Committee at the Faculty of Dentistry, Thamar University (Ref\#:2020005). Fractures of the mandible caused LPM to contract and displace the proximal bone fragment with a resultant change in LPM insertion position. Also, tumors and cysts affecting the infratemporal region might displace the LPM. So, patients with a history of fracture, tumors, or cysts, which might have affected the position and measurement of the LPM, were excluded from the study.

\section{Imaging and Measurements}

The CT scans were conducted using 32-slice spiral CT (Hitachi, Ltd., Supria, Japan) according to the following protocol: $120 \mathrm{kV}, 64$ to $200 \mathrm{mAs}, 0.5-\mathrm{mm}$ slice thickness, and $512 \times 512$ matrix. CT images were saved in digital imaging and communications in medicine (DICOM) format and were processed using the SimPlant software (SimPlant 3-D Pro; Materialize, Leuven, Belgium).

The axial image that crossed through the maximum width of the muscle was determined. We marked two perpendicular lines from the skin surface to the muscle as proposed by FU et al. ${ }^{23}$ The first line was located below the central zygomatic arch (first position), reached the lateral border of the muscle (distance $A$ ), and then extended to its medial border (distance B). The second line marked $5 \mathrm{~mm}$ posterior to the first line (second position), also reached the lateral border of the muscle (distance $C$ ), and then extended to its medial border (distance D) (Fig. 1). The distance to the center of the muscle in both sites was determined by the following equations:

$\begin{aligned} & \text { Distance to the center of the } \\ & \text { muscle in the first position }\end{aligned}=\frac{\text { distance } B-\text { distance } A}{2}+$ distance $A$ $\begin{aligned} & \text { Distance to the center of the } \\ & \text { muscle in the second position }\end{aligned}=\frac{\text { distance } \mathrm{D}-\text { distance } \mathrm{C}}{2}+$ distance $\mathrm{C}$

On coronal CT view, we determined the distance between the inferior border of the zygomatic arch and the point of entry

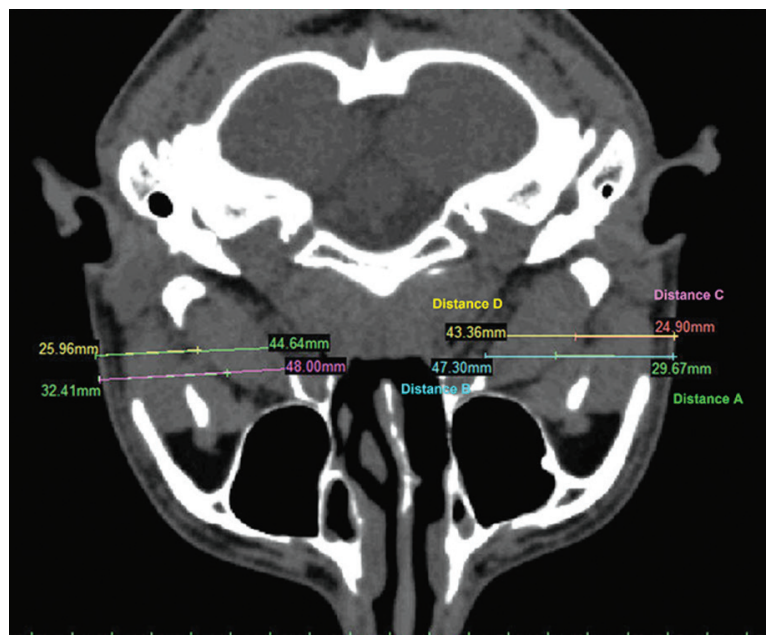

Fig. 1: Measurements at first and second positions from preauricular skin to medial and lateral borders of LPM

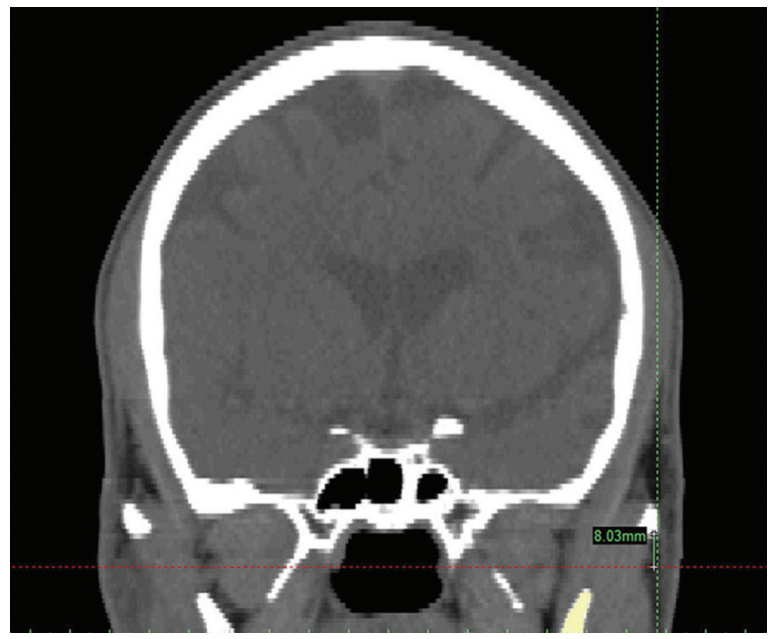

Fig. 2: Determination of the distance between the inferior border of the zygomatic arch and entry point on preauricular skin

on the preauricular skin (Fig. 2). The above measurements were done for the right and left sides. Measurements were done by two investigators independently who evaluated the CT images. The inter-rater reliability was tested by the intraclass correlation coefficient, and the level of agreement was perfect $($ ICC $=0.947$; $p$-value $<0.001)$.

\section{Statistical Analysis}

Data analysis was processed using SPSS v20.0 statistical software. Descriptive statistics, including mean, standard deviation, and minimum and maximum values, were calculated for the various measurements. Independent samples $t$-tests were used for the differences between male and female subjects and between right and left sides. The significance level was predetermined at 0.05 for all tests.

\section{Results}

The study population comprised 160 subjects [ 90 (56.25\%) males, $70(43.75 \%)$ females]. The mean age was $45.3 \pm 12.3$ years for males, ranging from 18 to 75 years; and $46.4 \pm 10.4$ years for females, 
Table 1: Mean distances and differences between right and left sides at the first and second positions ( $\mathrm{mm}$ )

\begin{tabular}{|c|c|c|c|c|c|c|}
\hline & \multirow[b]{2}{*}{ Mean $\pm S D$} & \multirow[b]{2}{*}{ Min-Max } & \multirow[b]{2}{*}{ Mean difference } & \multicolumn{2}{|c|}{$95 \% \mathrm{Cl}$ of difference } & \multirow[b]{2}{*}{$p$} \\
\hline & & & & Lower & Upper & \\
\hline \multicolumn{7}{|c|}{ Measurements in the first position } \\
\hline Right $(N=160)$ & $35.32 \pm 3.70$ & $27.12-41.7$ & \multirow{2}{*}{0.73} & \multirow{2}{*}{-0.13} & \multirow{2}{*}{1.59} & \multirow{2}{*}{0.094} \\
\hline Left $(N=160)$ & $34.58 \pm 4.10$ & $26.31-40.9$ & & & & \\
\hline \multicolumn{7}{|c|}{ Measurements in the second position } \\
\hline Right $(N=160)$ & $32.09 \pm 2.80$ & $24.81-37.17$ & \multirow{2}{*}{0.30} & \multirow{2}{*}{-0.34} & \multirow{2}{*}{0.93} & \multirow{2}{*}{0.358} \\
\hline Left $(N=160)$ & $31.80 \pm 2.98$ & $24.75-37.14$ & & & & \\
\hline
\end{tabular}

Table 2: Mean distances and differences between males and females at the first and second positions ( $\mathrm{mm}$ )

\begin{tabular}{|c|c|c|c|c|c|c|}
\hline & \multirow[b]{2}{*}{ Mean $\pm S D$} & \multirow[b]{2}{*}{ Min-Max } & \multirow[b]{2}{*}{ Mean difference } & \multicolumn{2}{|c|}{ 95\% Cl of difference } & \multirow[b]{2}{*}{$p$} \\
\hline & & & & Lower & Upper & \\
\hline \multicolumn{7}{|c|}{ Measurements in the first position } \\
\hline Male $(N=90)$ & $36.29 \pm 2.61$ & $31.11-41.6$ & \multirow{2}{*}{3.05} & \multirow{2}{*}{2.13} & \multirow{2}{*}{3.98} & \multirow{2}{*}{$<0.001$} \\
\hline Female $(N=70)$ & $33.23 \pm 3.29$ & $27.73-38.85$ & & & & \\
\hline \multicolumn{7}{|c|}{ Measurements in the second position } \\
\hline Male $(N=90)$ & $33.09 \pm 1.85$ & $29.64-42.81$ & \multirow{2}{*}{2.62} & \multirow{2}{*}{1.81} & \multirow{2}{*}{3.44} & \multirow{2}{*}{$<0.001$} \\
\hline Female $(N=70)$ & $30.47 \pm 3.02$ & $36.91-35.26$ & & & & \\
\hline
\end{tabular}

ranging from 19 to 70 years. The vertical distance on coronal CT from below the inferior border of the mid zygomatic arch to the skin point of measurement ranged from 7.5 to $10 \mathrm{~mm}$ in males and from 7 to $10 \mathrm{~mm}$ in females.

The mean distance at the first position to the muscle center was $35.31 \pm 3.69 \mathrm{~mm}$ on the right side and $34.58 \pm 4.10 \mathrm{~mm}$ on the left side. At the second position, the mean distance was $32.09 \pm 2.80 \mathrm{~mm}$ on the right side and $31.79 \pm 2.98 \mathrm{~mm}$ on the left side. There were no statistically significant differences between right and left sides at the first and second positions ( $p$-value $=0.094$ and $p$-value $=0.358$, respectively). More details are presented in Table 1.

As shown in Table 2, the mean distances in males at the first and second positions were $36.28 \pm 2.6$ and $33.09 \pm 1.84 \mathrm{~mm}$, respectively. While in females, these distances were $33.23 \pm 3.29$ and $30.46 \pm 3.02 \mathrm{~mm}$, respectively. There were highly statistically significant differences between males and females regarding the first (mean diff. $=3.05 \mathrm{~mm} ; p$-value $<0.001$ ) and second (mean diff. $=2.62 \mathrm{~mm} ; p$-value $<0.001$ ) positions.

\section{Discussion}

$\mathrm{CT}$ is a valuable tool in the diagnosis of different conditions and is useful for defining the anatomical structures and recording their measurements. Many authors ${ }^{32-39}$ used CT for studying different anatomical structures in the maxillofacial region. LPM is an essential component in masticatory function and TMD genesis, and sometimes there is a need for targeting and injecting the muscle. ${ }^{40}$ In the current study, the measuring point on the skin below the zygomatic arch, which coincides with the maximum width of the muscle, was 7 to $9 \mathrm{~mm}$ for females and 7.5 to $10 \mathrm{~mm}$ for males. Similarly, Fu et al. ${ }^{23}$ proposed an insertion point of $10 \mathrm{~mm}$ below the zygomatic arch. In contrast, Orfanos et al. ${ }^{41}$ suggested needle insertion at 5 to $6 \mathrm{~mm}$ inferior to the lower border of the zygomatic arch. However, the maximum muscle width was not mentioned as a target point in their study. Most of the previous studies, ${ }^{20,24,41-43}$ which reported on injection of LPM extraorally, lack the information about how deep the needle can be inserted and where the maximum width of the muscle could be found.

In our study, we measured the distances to the lateral and medial borders of the muscle and mathematically calculated the distance to the muscle center because the muscle borders can be easily identified and marked on CT. The distance from preauricular skin to the center of LPM (the first position) was slightly higher on the right side than on the left side. When the distance was measured at the second position, it was found to be lower on both sides. However, the differences between right and left sides at each position were statistically not significant.

The distances to the muscle center in the first and second positions were longer in males than in females. Comparison with the scarce available literature will be limited. Fu et al. ${ }^{23}$ and Alexoudi et al. ${ }^{19}$ have reported similar findings. They found that the distance from skin to LPM was about 30 to $40 \mathrm{~mm}$. Similarly, in a study on a human cadaver, the distance was measured and found to be $35 \mathrm{~mm}$ for the superior head of the LPM muscle. ${ }^{44}$

In contrast to our findings, Mahan et al. ${ }^{31}$ recommended a more insertion depth ranged from 35 to $50 \mathrm{~mm}$. This difference could be the result of using different insertion points on the skin and different angulation.

Although the study could clearly investigate the normal range for the LPM injection in the adult population, a number of limitations should be acknowledged. The sample size was taken from one area, so the results might be limited to the study population. This study did not evaluate the clinical effectiveness of the proposed injection approach. Future randomized controlled trials should include these guidelines for the management of disorders that need LPM injection or needling to further evaluate its clinical effectiveness. 


\section{Conclusion}

This radiographic study suggests that injection of the LPM can be properly performed at 7 to $10 \mathrm{~mm}$ below the mid zygomatic arch, and the needle could be inserted, in males, approximately 36 and $33 \mathrm{~mm}$ in the recommended first and second positions, respectively, while in females, shorter insertion distances by about $3 \mathrm{~mm}$ should be used in both positions.

\section{References}

1. Honée GL. The anatomy of the lateral pterygoid muscle. Acta Morphol Neerl Scand 1972;10(4):331-340. PMID: 4657703.

2. Standring S, Gray H. Gray's anatomy : the anatomical basis of clinical practice. 40th ed. Edinburgh:Churchill Livingstone/Elsevier; $2008.538 \mathrm{p}$.

3. Usui A, Akita K, Yamaguchi K. An anatomic study of the divisions of the lateral pterygoid muscle based on the findings of the origins and insertions. Surg Radiol Anat 2008;30(4):327-333. DOI: 10.1007/ s00276-008-0329-2.

4. Rees $L A$. The structure and function of the mandibular joint. Br Dent J 1954;96:125-133.

5. Sugisaki M, Komori E, Nakazawa M, et al. Anatomical studies of the lateral pterygoid muscle by the superior approach and a review of the literature. Jpn J Oral Maxil Surg 1986;32(5):718-730. DOI: 10.5794/ jjoms.32.718.

6. Porter MR. The attachment of the lateral pterygoid muscle to the meniscus. J Prosthet Dent 1970;24(5):555-562. DOI: 10.1016/00223913(70)90063-6.

7. Troiano MF. New concept of the insertion of the lateral pterygoid muscle. J Oral Surg 1967;25(4):337-340. PMID: 5229276.

8. Akita K, Shimokawa T, Sato T. Positional relationships between the masticatory muscles and their innervating nerves with special reference to the lateral pterygoid and the midmedial and discotemporal muscle bundles of temporalis. J Anat 2000;197(Pt 2):291-302. DOI: 10.1046/j.1469-7580.2000.19720291.x.

9. Akita K, Shimokawa T, Sato T. An anatomic study of the positional relationships between the lateral pterygoid muscle and its surrounding nerves. Eur J Anat 2003;7(S1):5-14.

10. Foucart J, Girin J, Carpentier P. Innervation of the human lateral pterygoid muscle. Surg Radiol Anat 1998;20(3):185-189. DOI: 10.1007/ BF01628893.

11. Smith RD, Marcarian $\mathrm{H}$. The neuromuscular spindles of the lateral pterygoid muscle. Anat Anz 1967;120(1):47. PMID: 4232565.

12. McNamara Jr JA. The independent functions of the two heads of the lateral pterygoid muscle. Am J Anat 1973;138(2):197-205. DOI: 10.1002/ aja.1001380206.

13. Wilkinson T. The relationship between the disk and the lateral pterygoid muscle in the human temporomandibular joint. J Prosthet Dent 1988;60(6):715-724. DOI: 10.1016/0022-3913(88)90406-4.

14. Arıncı A, Güven E, Yazar M, et al. Effect of injection of botulinum toxin on lateral pterygoid muscle used together with the arthroscopy in patients with anterior disk displacement of the temporomandibular joint. Kulak Burun Bogaz Ihtis Derg 2009;19(3):122-129. PMID: 19857189.

15. Mendes RA, Upton L. Management of dystonia of the lateral pterygoid muscle with botulinum toxin $\mathrm{A}$. Br J Oral Maxillofac Surg 2009;47(6):481-483. DOI: 10.1016/j.bjoms.2008.08.010.

16. Goodpaster BH, Thaete FL, Kelley DE. Composition of skeletal muscle evaluated with computed tomography. Ann N Y Acad Sci 2000;904(1):18-24. DOI: 10.1111/j.1749-6632.2000.tb06416.x.

17. Lell MM, Wildberger JE, Alkadhi $\mathrm{H}$, et al. Evolution in computed tomography: the battle for speed and dose. Invest Radiol 2015;50(9):629-644. DOI: 10.1097/RLI.0000000000000172.

18. Mazonakis M, Damilakis J. Computed tomography: what and how does it measure? Eur J Radiol 2016;85(8):1499-1504. DOI: 10.1016/j. ejrad.2016.03.002.

19. Alexoudi A, Dalivigka Z, Siatouni A, et al. Oromandibular dystonia: a case report of the lateral pterygoid muscle involvement and treatment with botulinum toxin A. Clin Pract 2016;6(3):862. DOI: 10.4081/cp.2016.862.

20. Martos-Díaz P, Rodríguez-Campo F, Bances-Del Castillo $R$, et al. Lateral pterygoid muscle dystonia. A new technique for treatment with botulinum toxin guided by electromyography and arthroscopy. Med Oral Pathol Oral Cir Bucal 2011;16(1):e96-e99. DOI: 10.4317/ medoral.16.e96.

21. Daelen B, Thorwirth V, Koch A. Treatment of recurrent dislocation of the temporomandibular joint with type A botulinum toxin. Int J Oral Maxillofac Surg 1997;26(6):458-460. DOI: 10.1016/s09015027(97)80014-8.

22. Stark TR, Perez CV, Okeson JP. Recurrent TMJ dislocation managed with botulinum toxin type a injections in a pediatric patient. Pediatr Dent 2015;37(1):65-69. PMID: 25685976.

23. Fu KY, Chen HM, Sun ZP, et al. Long-term efficacy of botulinum toxin type $A$ for the treatment of habitual dislocation of the temporomandibular joint. Br J Oral Maxillofac Surg 2010;48(4):281284. DOI: 10.1016/j.bjoms.2009.07.014.

24. Sanjuan-Sanjuan A, Alamillos-Granados FJ, Dean-Ferrer A, et al. Electromyography assisted application of botulinum toxin in pterygoid musculature for the treatment of masticatory myofascial pain. Rev Esp Cirug Oral Maxilofac 2019;41(2):54-60. DOI: 10.20986/ recom.2019.1017/2018.

25. Bakke M, Møller E, Werdelin LM, et al. Treatment of severe temporomandibular joint clicking with botulinum toxin in the lateral pterygoid muscle in two cases of anterior disc displacement. Oral Surg Oral Med Oral Pathol Oral Radiol Endod 2005;100(6):693-700. DOI: 10.1016/j.tripleo.2004.11.019.

26. Itoh $\mathrm{K}$, Asai $\mathrm{S}$, Ohyabu $\mathrm{H}$, et al. Effects of trigger point acupuncture treatment on temporomandibular disorders: a preliminary randomized clinical trial. J Acupunct Meridian Stud 2012;5(2):57-62. DOI: 10.1016/j.jams.2012.01.013.

27. Gonzalez-Perez LM, Infante-Cossio P, Granados-Nunez M, et al. Deep dry needling of trigger points located in the lateral pterygoid muscle: efficacy and safety of treatment for management of myofascial pain and temporomandibular dysfunction. Med Oral Patol Oral Cir Bucal 2015;20(3):e326. DOI: 10.4317/medoral.20384.

28. Brodsky MA, Swope DM, Grimes D. Diffusion of botulinum toxins. Tremor Other Hyperkinet Mov 2012;2. DOI: 10.7916/D88W3C1M.

29. Shaari CM, George E, Wu BL, et al. Quantifying the spread of botulinum toxin through muscle fascia. Laryngoscope 1991;101(9):960-964. DOI: 10.1288/00005537-199109000-00006.

30. Hallett M. Explanation of timing of botulinum neurotoxin effects, onset and duration, and clinical ways of influencing them. Toxicon 2015;107:64-67. DOI: 10.1016/j.toxicon.2015.07.013.

31. Mahan PE, Wilkinson TM, Gibbs $\mathrm{CH}$, et al. Superior and inferior bellies of the lateral pterygoid muscle EMG activity at basic jaw positions. J Prosthet Dent 1983;50(5):710-718. DOI: 10.1016/00223913(83)90214-7.

32. Lee DH, Yu HS. Masseter muscle changes following orthognathic surgery: a long-term three-dimensional computed tomography follow-up. Angle Orthod 2012;82(5):792-798. DOI: 10.2319/111911-717.1

33. Maki K, Miller A, Okano T, et al. Cortical bone mineral density in asymmetrical mandibles: a three-dimensional quantitative computed tomography study. Eur J Orthod 2001;23(3):217-232. DOI: 10.1093/ejo/23.3.217.

34. Kaviani F, Rashid RJ, Shahmoradi Z, et al. Detection of foreign bodies by spiral computed tomography and cone beam computed tomography in maxillofacial regions. J Dent Res Dent Clin Dent Prospects 2014;8(3):166. DOI: 10.5681/joddd.2014.030.

35. Chan HJ, Woods M, Stella D. Mandibular muscle morphology in children with different vertical facial patterns: a 3-dimensional computed tomography study. Am J Orthod Dentofacial Orthop 2008;133(1):10. e1-10. e13. DOI: 10.1016/j.ajodo.2007.05.013.

36. Xu J, Yuasa K, Yoshiura K, et al. Quantitative analysis of masticatory muscles using computed tomography. Dentomaxillofac Radiol 1994;23(3):154-158. DOI: 10.1259/dmfr.23.3.7835516. 
37. Tsiklakis K, Syriopoulos K, Stamatakis H. Radiographic examination of the temporomandibular joint using cone beam computed tomography. Dentomaxillofac Radiol 2004;33(3):196-201. DOI: 10.1259/dmfr/27403192.

38. Ludlow JB, Laster WS, See M, et al. Accuracy of measurements of mandibular anatomy in cone beam computed tomography images. Oral Surg Oral Med Oral Pathol Oral Radiol Endod 2007;103(4):534542. DOI: 10.1016/j.tripleo.2006.04.008.

39. Kuribayashi A, Watanabe $\mathrm{H}$, Imaizumi A, et al. Bifid mandibular canals: cone beam computed tomography evaluation. Dentomaxillofac Radiol 2010;39(4):235-239. DOI: 10.1259/dmfr/66254780.

40. Pons $M$, Meyer C, Euvrard E, et al. MR-guided navigation for botulinum toxin injection in the lateral pterygoid muscle. First results in the treatment of temporomandibular joint disorders. J Stomatol Oral Maxillofac Surg 2019;120(3):188-195. DOI: 10.1016/j. jormas.2018.11.002.
41. Orfanos T, Sarinnaphakorn L, Murray G, et al. Placement and verification of recording electrodes in the superior head of the human lateral pterygoid muscle. Arch Oral Biol 1996;41(5):493-503. DOI: 10.1016/0003-9969(95)00142-5.

42. Martín-Granizo R, Maniegas L, Colorado L, et al. Direct infiltration of botulinum toxin into the pterygoid lateral muscle for repositioning of the disc during arthroscopy of the temporomandibular joint. Br J Oral Maxillofac Surg 2018;56(8):769-771. DOI: 10.1016/j.bjoms.2018.07.014.

43. Shalash AS, Abushouk Al, Elsherbeny MY, et al. Refractory open jaw oromandibular tardive dystonia with a sensory trick, treated with botulinum toxin: a case report. Neurol India 2019;67(4):1110. DOI: 10.4103/0028-3886.266235.

44. Koole P, Beenhakker F, de Jongh $\mathrm{HJ}$, et al. A standardized technique for the placement of electrodes in the two heads of the lateral pterygoid muscle. CRANIO ${ }^{\circledR} 1990 ; 8(2): 154-162$. DOI: $10.1080 / 08869634.1990 .11678309$ 